\title{
RECORDAÇÕES DE UMA AFRO-BRASILEIRA E OUTROS MOVIMENTOS
}

\begin{abstract}
Anselmo Peres Alós é Professor-Leitor de Língua Portuguesa, Literatura e Cultura Brasileiras no Instituto Superior de Ciências e Tecnologia de Moçambique (ISCTEM). Doutor em Literatura Comparada pela UFRGS. Publicações recentes: "Madame Satã e a encenação do feminino" (Gênero, Niterói, v. 8, 2008, p. 369-385), "Literatura e intervenção política na América Latina" (Cadernos de Letras da UFF, Niterói, no 38, p. 139-162, 2009), "Heterotopias do desassossego" (Cerrados, Brasília, v. 27, p. 231 - 249, 2009) e "Um exercício comparatista da leitura queer" (Crítica Cultural, Palhoça/SC, v. 4, p. 65 - 79, 2009).

E-mail: anselmoperesalos@yahoo.com.br.
\end{abstract}

\begin{abstract}
Resumo
Em seu primeiro livro de poemas, Poemas da recordação e outros movimentos (Belo Horizonte, Nandyala, 2008. 72p.), Conceição Evaristo explora temas recorrentes em suas obras em prosa, tais como a constituição de espaços de memória e da subjetividade da mulher negra brasileira. Para tanto, articula em sua poética pessoal questões relativas à representação de gênero, raça e classe social.
\end{abstract}

\begin{abstract}
In her first book of poetry, Poemas $d a$ recordação e outros movimentos (Belo Horizonte, Nandyala, 2008. 72p.), Conceição Evaristo explores recurrent themes of her prose works, like the constitution of places of memory and of Brazilian black women subjectivity. For that, she works in her personal poetics questions related to the gender, race and class representation
\end{abstract}

A estréia de Conceição Evaristo nas letras brasileiras foi relativamente tardia, remontando aos inícios dos anos 90, quando começa a colaborar em periódicos literários. Um dos principais meios nos quais Evaristo publica é a série Cadernos Negros, fundada pelo grupo Quilombohoje Literatura, coletivo de escritores fundado em 1980 com o objetivo de discutir e aprofundar a experiência afro-brasileira na literatura, incentivar o hábito da leitura e promover estudos, pesquisas e diagnósticos sobre literatura e cultura negra. Em 2003, a escritora publica o seu primeiro livro individual, Ponciá Vicêncio, romance que logo chamou a atenção da crítica, particularmente pela maneira através da qual a autora articula a reflexão sobre questões de gênero, raça e classe social. Três anos depois, Evaristo publica Becos da Memória. Ainda que, em termos de publicação, este seja o segundo romance de Evaristo, a escrita desta narrativa remonta à década de oitenta. Tal como a própria escritora assinala, o livro se encontrava pronto desde 1988, mas acabou ficando no fundo da gaveta, adormecido. Chegou-se a cogitar uma publicação através da Fundação Palmares, ainda em 1988, mas "o livro já havia se acostumado ao abandono. E só agora, quase 20 anos depois de escrito, acontece sua publicação" (EVARISTO, 2006, p. 10).

Em seu mais recente livro, Poemas da Recordação e Outros Movimentos (2008), aparecem novamente, tal como na obra em prosa, os motivos da diáspora negra, da autoria feminina e da construção da identidade negra como temas recorrentes. Em seu exercício de expressão, o lirismo dos poemas de Evaristo trabalha explicitamente no sentido de instaurar uma retórica da resistência, dando especial atenção ao desmantelamento dos estereótipos em torno do negro e da mulher (e mais especificamente, da mulher negra) no imaginário brasileiro. Tal como já afirmou 
Eduardo de Assis Duarte, as constantes temáticas da obra de Conceição Evaristo a inserem em um continuum de autores afro-descendentes para os quais as questões étnico-raciais não são apenas um aspecto da realidade brasileira a ser incorporado em sua escrita, mas uma experiência constitutiva de suas subjetividades, signo indelével da diferença corporificado por tais autores:

A vertente inaugurada por Maria Firmina dos Reis, contemplando o resgate de uma memória coletiva apagada pelo discurso colonial, terá seqüência, em seus diversos matizes, na prosa afro-brasileira: passa por Cruz e Souza e por Lima Barreto; por Ruth Guimarães e por Carolina Maria de Jesus; e deságua em autores contemporâneos, tais como Oswaldo de Camargo, Geni Guimarães, Conceição Evaristo e tantos outros (DUARTE, 2006, p. 308).

Há uma tensão dialética entre a busca pela própria voz e a resistência ao silêncio histórico imposto aos afro-descendentes no Brasil. Como alternativa para enfrentar este silêncio secular, Evaristo realiza uma arqueologia afetiva, escavando nas memórias familiares elementos que permitam ao sujeito poético afirmar-se no mundo ao mesmo tempo em que reconstitui as suas origens e concretiza sua identidade. Na temática abordada em seus poemas, Evaristo retoma o princípio matrilinear da organização social, presente em muitos grupos étnicos bantu, como possibilidade de estruturar a genealogia de sua própria voz, tal como se pode vislumbrar nestes versos do poema " $\mathrm{Da}$ Mãe":

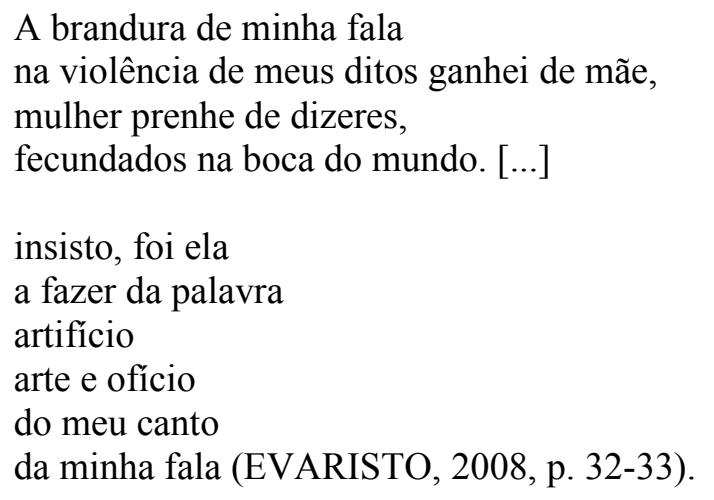

A oralidade encontra-se com a busca pelas origens, e o papel dinâmico da mulher negra emerge neste contexto através da metáfora da mulher "prenhe de dizeres", detentora das memórias coletivas de seu povo, como escreve a autora em "VozesMulheres":

A voz de minha mãe ecoou baixinho revolta no fundo das cozinhas alheias debaixo das trouxas roupagens sujas dos brancos pelo caminho empoeirado 
rumo à favela (EVARISTO, 2008, p. 10).

$\mathrm{Na}$ continuidade desse percurso pelos meandros de um passado silenciado, surge a voz do eu-lírico, a qual ecoa "versos perplexos / com rimas de sangue / e fome" (EVARISTO, 2008, p. 10). A voz da filha do eu-lírico agrega "as vozes mudas caladas / engasgadas nas gargantas" que a antecederam. Todavia, "[n]a voz de minha filha / se fará ouvir a ressonância / o eco da vida-liberdade". Mais do que restaurar as heranças africanas através da construção de uma genealogia matrilinear, esta genealogia subverte o histórico de silêncio racista e patriarcal, ao mesmo tempo em que assegura, no eco da vida-liberdade da última mulher negra mencionada no poema, uma afirmação de resistência e de espaço conquistado.

No projeto poético de Conceição Evaristo, ganha destaque a preocupação de construir uma identidade afirmativa para a mulher negra, cujo papel nas cadeias produtivas do imaginário nacional foi apagado em função dos resquícios da herança escravocrata do Brasil. É o que se pode vislumbrar neste fragmento do poema "EuMulher":

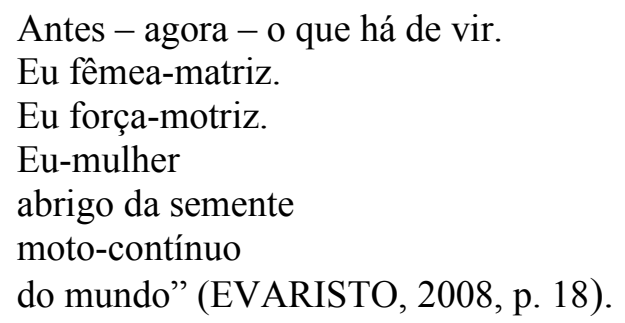

Nestes versos, o eu-lírico projetado pela autora reconhece a mulher como sujeito ativo na construção de sua história, tanto a individual quanto a coletiva. Para tanto, a autora coloca em paralelo a participação das mulheres no mundo social ao referenciar funções tais como a manutenção da vida (através das imagens da fêmea-motriz e do abrigo da semente) e as forças de produção material e simbólica (em função das metáforas cristalizadas nas imagens da força-motriz e do moto-contínuo do mundo).

A maternidade, uma das constantes temáticas nos poemas de Evaristo, poderia ser lida como um deslize rumo a uma concepção essencialista do papel da mulher na sociedade contemporânea. Contudo, vale lembrar que, historicamente, o direito das mulheres negras ao exercício da maternidade foi historicamente apagado, em função da objetificação das mulheres pelo patriarcado escravocrata brasileiro. Insistir nestas imagens configura um deliberado exercício de recuperar, através das memórias e da enunciação poética, a performance de uma função social que durante um longo período da história foi interditado às mulheres afro-brasileiras, como afirma Sonia Maria Giacomini:

Para que a escrava se transformasse em mãe-preta da criança branca, foi-lhe bloqueada 
a possibilidade de ser mãe de seu filho preto. [...] a escrava transformada em ama-deleite conhece, na negação de sua maternidade, a negação de sua condição de mulher. Por paradoxal que pareça, é sua fisiologia feminina - capacidade de lactação - que a contrapõe à realização de sua potencialidade materna (GIACOMINI, 1988, p. 57-58).

A trajetória da escrita poética de Conceição Evaristo faz ainda com que o/a leitor/a aventure-se em um universo lírico marcado pela resistência feminina em relação à submissão, seja ela com relação às dinâmicas do poder na seara do gênero, seja com relação ao pertencimento étnico-racial. "Fêmea-Fênix" textualiza esta postura disruptiva de resistência das mulheres afro-brasileiras:

\author{
Deserto-me eu mulher e não temo \\ sei do cativante vazio da miragem, \\ e quando o pavor \\ em mim aloja, não temo o medo, \\ sei que posso me fundir ao só, \\ e em solo ressurgir inteira \\ com o corpo banhado pelo suor \\ da faina" (EVARISTO, 2008, p. 30).
}

O eu-lírico, declinado no feminino, não sucumbe diante das situações adversas que geram pavor e medo, ou mesmo perante o cansaço da faina. Ao contrário disso, toma consciência da sua capacidade de ressurgir inteira tal qual a fênix, "que tem o poder, depois de se consumir em uma fogueira, de renascer de suas cinzas" (CHEVALIER, 1996, p. 422). Tal qual a fênix que renasce das próprias cinzas, o eulírico afirma: "posso me lançar ao fogo / e da fogueira me sair inunda, / com o corpo amigado pelo odor / da chama" (EVARISTO, 2008, p. 30).

Prosseguindo na tentativa de autodefinição, o eu-lírico aventura-se em um processo de escrever-se e de escrever o outro, como no poema "Menina":

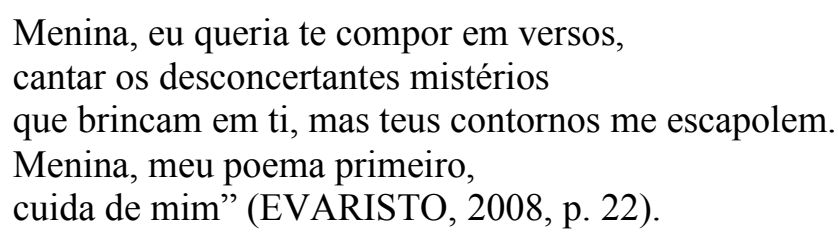

Dedicado à sua filha Ainá, este poema estabelece um diálogo no qual o eu-lírico confessa, simultaneamente, o desejo de (d)escrever a filha em seus "desconcertantes mistérios". Tal projeto, no entanto, não é levado a cabo, uma vez que o sujeito instituído pela escrita poética necessita, antes disso, cumprir a escrita de si mesmo. Em um gesto retórico que ecoa postulados foucaultianos da escrita e do cuidado de si, Evaristo aponta que o devir do sujeito só é possível neste gesto dialógico de contato intersubjetivo.

Ao invés de subsumir a memória coletiva das mulheres afro-brasileiras em uma narrativa fundacional de veio nacionalista, tal qual o projeto do romantismo oitocentista 
brasileiro, Evaristo insiste na demarcação das especificidades. Ao invés de dar vazão ao primado do pluribus unum, que vê no nacionalismo uma meta-narrativa capaz de abrigar pacificamente as diferenças e de apagar o legado histórico de expropriações vivenciados pelas mulheres afro-brasileiras, a poesia de Conceição Evaristo textualiza as dores do passado, em um projeto poético que busca a identidade sem abrir mão das suas especificidades de mulher afro-brasileira.

\section{Referências bibliográficas}

CHEVALIER, Jean e GHEERBRANT, Alain. Dicionário de Símbolos. Rio de Janeiro: José Olympio, 1996.

DUARTE, Eduardo de Assis. "O Bildungsroman afro-brasileiro de Conceição Evaristo”. Estudos Feministas. Florianópolis, 14 (1): 305-308, janeiro-abril de 2006.

EVARISTO, Conceição. Poemas da recordação e outros movimentos. Belo Horizonte: Nandyala, 2008.

. "Conversa com o leitor: da construção de Becos". In: . Becos da Memória. Belo Horizonte: Mazza, 2006. p. 10.

. Ponciá Vicêncio. Belo Horizonte: Mazza, 2003.

GIACOMINI, Sonia Maria. Mulher e escrava: uma introdução histórica ao estudo da mulher negra no Brasil. Rio de Janeiro: Vozes, 1988. 